\title{
Article \\ Repurposing Eltrombopag for Multidrug Resistant Staphylococcus aureus Infections
}

\author{
Hyunjung Lee ${ }^{1}$, Jaehoan Lee ${ }^{1}$, Juchan Hwang ${ }^{1}\left(\mathbb{D}\right.$, Sinyoung Park $^{2}$, Namyoul Kim ${ }^{3}$, Kideok Kim ${ }^{3}{ }^{\mathbb{D}}$, \\ Honggun Lee ${ }^{3}$, David Shum ${ }^{3}$ and Soojin Jang ${ }^{1, *}$ \\ 1 Antimicrobial Resistance Laboratory, Institut Pasteur Korea, Seongnam-si 13488, Korea; \\ hyunjung.lee@ip-korea.org (H.L.); Jellyfocus@outlook.com (J.L.); juchan.hwang@ip-korea.org (J.H.) \\ 2 Animal Facility Team, Institut Pasteur Korea, Seongnam-si 13488, Korea; psy6600@daum.net \\ 3 Screening Discovery Platform, Institut Pasteur Korea, Seongnam-si 13488, Korea; skaduf@hanmail.net (N.K.); \\ kideok.kim@ip-korea.org (K.K.); honggun.lee@ip-korea.org (H.L.); david.shum@ip-korea.org (D.S.) \\ * Correspondence: soojin.jang@ip-korea.org; Tel.: +82-31-8018-8194
}

check for updates

Citation: Lee, H.; Lee, J.; Hwang, J.; Park, S.; Kim, N.; Kim, K.; Lee, H.; Shum, D.; Jang, S. Repurposing Eltrombopag for Multidrug Resistant Staphylococcus aureus Infections. Antibiotics 2021, 10, 1372. https:// doi.org/10.3390/antibiotics10111372

Academic Editor: Yinduo Ji

Received: 18 October 2021

Accepted: 5 November 2021

Published: 9 November 2021

Publisher's Note: MDPI stays neutral with regard to jurisdictional claims in published maps and institutional affiliations.

Copyright: (c) 2021 by the authors. Licensee MDPI, Basel, Switzerland. This article is an open access article distributed under the terms and conditions of the Creative Commons Attribution (CC BY) license (https:// creativecommons.org/licenses/by/ $4.0 /)$.

\begin{abstract}
The continuous rise of antimicrobial resistance urgently demands new therapeutic agents for human health. Drug repurposing is an attractive strategy that could significantly save time delivering new antibiotics to clinics. We screened 182 US Food and Drug Administration (FDA)approved drugs to identify potential antibiotic candidates against Staphylococcus aureus, a major pathogenic bacterium. This screening revealed the significant antibacterial activity of three small molecule drugs against S. aureus: (1) LDK378 (Ceritinib), an anaplastic lymphoma kinase (ALK) inhibitor for the treatment of lung cancer, (2) dronedarone $\mathrm{HCl}$, an antiarrhythmic drug for the treatment of atrial fibrillation, and (3) eltrombopag, a thrombopoietin receptor agonist for the treatment of thrombocytopenia. Among these, eltrombopag showed the highest potency against not only a drug-sensitive $S$. aureus strain but also 55 clinical isolates including 35 methicillin-resistant S. aureus (Minimum inhibitory concentration, $\mathrm{MIC}$, to inhibit $50 \%$ growth $\left[\mathrm{MIC}_{50}\right]=1.4-3.2 \mathrm{mg} / \mathrm{L}$ ). Furthermore, we showed that eltrombopag inhibited bacterial growth in a cell infection model and reduced bacterial loads in infected mice, demonstrating its potential as a new antibiotic agent against S. aureus that can overcome current antibiotic resistance.
\end{abstract}

Keywords: Staphylococcus aureus; MRSA; drug repurposing; eltrombopag; in vivo efficacy

\section{Introduction}

Antibiotic resistance is one of the greatest threats to global public health, which could cause the next pandemic. Development of effective therapeutic agents is vital to prepare for a battle against antibiotic resistant infections. S. aureus is a leading cause of bacterial infections worldwide and remains a major public health concern due to the emergence and rapid spread of drug-resistant strains, such as methicillin-resistant S. aureus (MRSA) and the vancomycin-resistant strain that was reported in the United States in 2002 [1]. The World Health Organization (WHO) has listed Staphylococcus aureus as a priority pathogen for the urgent development of new antibiotics [2]. However, the development of new antibiotics for clinical usage can take more than 10 years. Alternatively, repositioning currently approved drugs that may have antimicrobial [3] or antiviral [4] activities could shorten the development time substantially.

In this study, we assessed 182 Food and Drug Administration (FDA)-approved drugs for their potential antimicrobial activity against $S$. aureus. Three drugs demonstrated promising results - Ceritinib, dronedarone $\mathrm{HCl}$, and eltrombopag. Among them, eltrombopag, a non-peptide agonist of the thrombopoietin receptor (TpoR) initially approved for the treatment of thrombocytopenia, showed the greatest efficacy against $S$. aureus including 55 clinical isolates. We confirmed that not only in vitro but also ex vivo and in vivo efficacy 
of eltrombopag demonstrating that it is a good drug candidate for treatment of multi-drug resistant $S$. aureus infections.

\section{Results and Discussion}

\subsection{Primary Screening}

A total of 182 FDA-approved drugs were selected from the compound collection at the Institut Pasteur Korea (IPK) and screened for antibacterial activities against $S$. aureus ATCC25923 at $10 \mu \mathrm{M}$. The primary screening identified 12 compounds that inhibited bacterial growth by more than $50 \%$ (Figure 1, Table 1), including 8 known to be antimicrobial molecules and 4 miscellaneous repositionable candidates: dronedarone $\mathrm{HCl}$, ceritinib, eltrombopag and ivacaftor. In this study ivacaftor, a drug for cystic fibrosis, was excluded for further investigation because antibacterial activity of ivacaftor has been reported against $S$. aureus [3]. The primary screening successfully identified all known antibiotics among the 182 FDA-approved drugs that were tested, validating the high fidelity of the antibacterial assay.

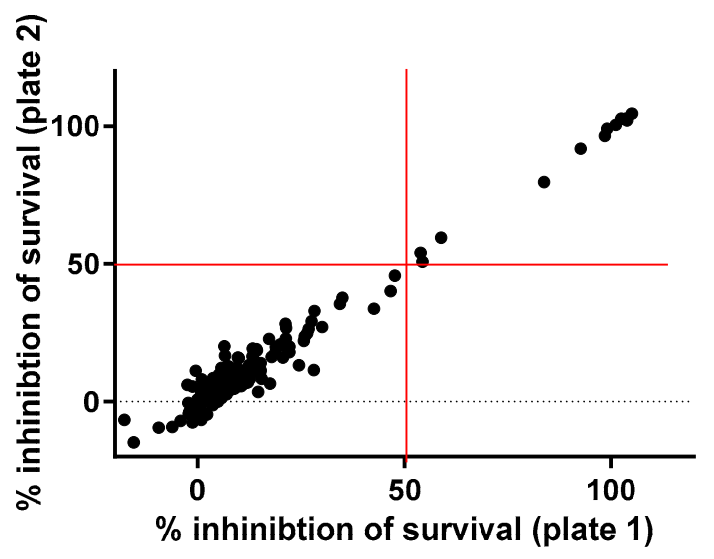

Figure 1. Primary screen of the drug library. A total of 182 FDA-approved compounds were tested against S. aureus at $10 \mu \mathrm{M}$. A total of 12 drugs inhibited the growth of bacteria by more than $50 \%$.

Table 1. Summary of selected molecules with antimicrobial activity.

Compound Name


Table 1. Cont.

\begin{tabular}{|c|c|c|c|}
\hline Compound Name & Compound Structure & $\%$ Inhibition $\pm \mathrm{SD}^{\mathrm{a}}$ & Class $^{b}$ \\
\hline Eltrombopag & & $100.8 \pm 0.5$ & $\begin{array}{l}\text { Thrombopoietin } \\
\text { receptor agonist }\end{array}$ \\
\hline Ivacaftor & & $104.8 \pm 0.4$ & $\begin{array}{l}\text { Cystic fibrosis } \\
\text { transmembrane } \\
\text { conductance regulator } \\
(\text { CFTR) potentiator }\end{array}$ \\
\hline Tedizolid (phosphate) & & $52.6 \pm 2.6$ & Antibiotic \\
\hline Fosfomycin sodium & & $53.9 \pm 0.1$ & Antibiotic \\
\hline Rosoxacin & & $92.2 \pm 0.6$ & Antibiotic \\
\hline
\end{tabular}


Table 1. Cont.

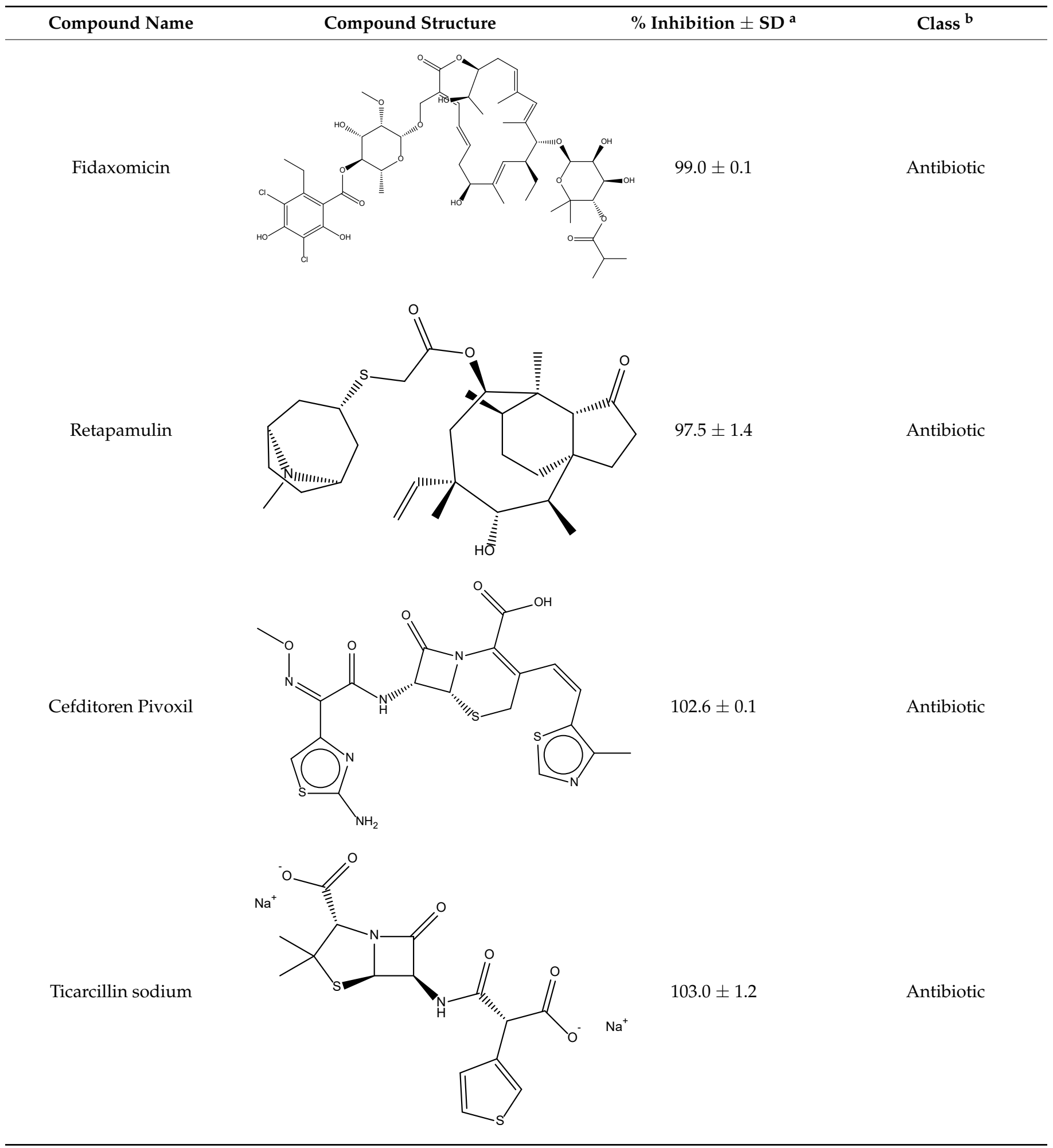


Table 1. Cont.

Compound Name Compound Structure

${ }^{a}$ Bacterial growth inhibition (\%) obtained from the primary screening in duplicate. ${ }^{\mathrm{b}}$ Classification of drug.

\subsection{Dose-Response Assay of Selected Repositionable Candidates}

We tested the three selected repositionable drug candidates against $S$. aureus ATCC25923 at concentrations ranging from $0.014 \mathrm{mg} / \mathrm{L}$ to $44.25 \mathrm{mg} / \mathrm{L}$ (using 2-fold dilutions) to confirm their antibacterial activities and determine their potencies with minimum inhibitory concentration (MIC) values (Figure 2A).

A

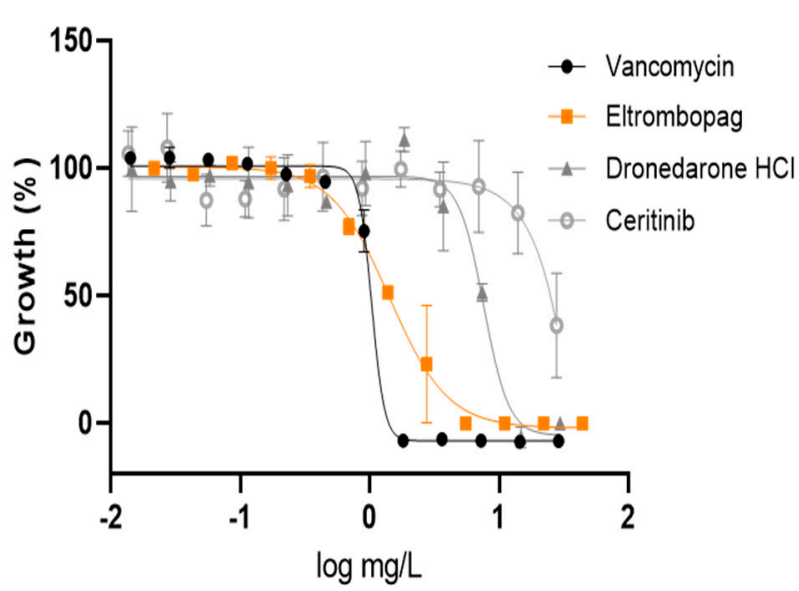

B

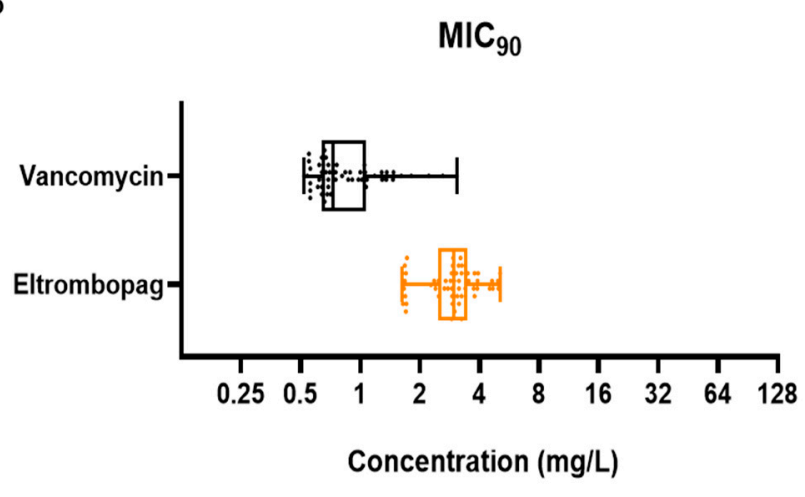

Figure 2. Antimicrobial activity of eltrombopag compound. (A) Dose-response curves for dronedarone $\mathrm{HCl}$, ceritinib, eltrombopag and vancomycin $(0.014-30 \mathrm{mg} / \mathrm{L}, 0.014-28 \mathrm{mg} / \mathrm{L}, 0.022-44.25 \mathrm{mg} / \mathrm{L}$ and $0.014-29 \mathrm{mg} / \mathrm{L})$ against $S$. aureus ATCC25923. The data represent the mean \pm SD ( $n=3$ per group). (B) Distribution of eltrombopag MIC 90 against MDR \#1-5, MSSA \#1-20 and MRSA \#1-30 strains.

Dronedarone $\mathrm{HCl}$ is a Class III antiarrhythmic drug that works to restore the normal sinus rhythm in patients with paroxysmal or persistent atrial fibrillation. Amiodarone, the parent drug of dronedarone $\mathrm{HCl}$, has shown antibacterial activity and has been suggested as a catheter lock to prevent bacterial infection [5]. Similarly, we found that the concentration that inhibits $50 \%$ of the bacterial growth $\left(\mathrm{MIC}_{50}\right)$ of dronedarone $\mathrm{HCl}$ is $7.6 \pm 0.7 \mathrm{mg} / \mathrm{L}$.

Several studies describe the antibacterial activities of anticancer drugs. Sorafenib, a human multi-kinase inhibitor approved as an anticancer drug, is active against S. aureus [6]. A developed analog of sorafenib, PK150, showed improved antibacterial activity [7]. Our screening also identified the antibacterial activity of ceritinib, an anticancer drug that inhibits anaplastic lymphoma kinase (ALK) [8]. The $\mathrm{MIC}_{50}$ of ceritinib in our study was $23.7 \pm 5.3 \mathrm{mg} / \mathrm{L}$ against $S$. aureus. Although its potency is not sufficient to serve as an 
independent antibiotic, ceritinib could be a seed molecule for further development, similar to sorafenib.

Eltrombopag was originally developed to treat certain conditions that lead to thrombocytopenia. Eltrombopag is a small molecule agonist of the platelet thrombopoietin receptor (TpoR) that binds to and stimulates TpoR, increasing the production of blood platelets [9]. We found that eltrombopag has the highest potency among the three identified repositioning candidates $\left(\mathrm{MIC}_{50}=1.5 \pm 0.1 \mathrm{mg} / \mathrm{L}\right)$. Since eltrombopag is an orally bioavailable drug, which is a beneficial feature for antibiotics, we performed subsequent investigations to demonstrate and validate the antibacterial activity of eltrombopag against clinically isolated and multidrug resistant $S$. aureus.

\subsection{Confirmation of Eltrombopag Activity against S. aureus Clinical Isolates and Other Bacterial Species}

We performed the antibacterial activity test of eltrombopag against fifty-five clinically isolates of $S$. aureus including 30 MRSA strains, some of which were resistant to multiple antibiotics such as fluoroquinolones (levofloxacin), tetracycline, erythromycin, beta-lactams (penicillin and methicillin), and second- and third-generation cephalosporins (cefoxitin, cefoperazone, and ceftriazone) with and without a beta-lactamase inhibitor (sulbactam) (Supplementary Table S1). Eltrombopag was active against all fifty-five clinical isolates (S. aureus MDR\#1-5, MSSA\#1-20, and MRSA\#1-30) within the range of MIC90 between 1.6 and $5.1 \mathrm{mg} / \mathrm{L}$ with a median value of $3.0 \mathrm{mg} / \mathrm{L}$, which was similar to observed activity against the drug-sensitive $S$. aureus. The result suggested that eltrombopag likely acts through an antibacterial mechanism distinct from those of current antibiotics (Figure $2 \mathrm{~B}$ and Supplementary Table S2). We next determined an antibacterial spectrum for eltrombopag against additional Gram-positive bacteria (Streptococcus pneumoniae) and Gram-negative bacteria (Pseudomonas aeruginosa, Acinetobacter baumannii, and Klebsiella pneumoniae). We found that eltrombopag efficiently inhibited pneumococcal growth $\left(\mathrm{MIC}_{50}=0.3 \mathrm{mg} / \mathrm{L}\right)$ but showed no activity against the three Gram-negative bacteria (Supplementary Table S2). These results suggested that eltrombopag likely has the activity against Gram-positive bacteria but not Gram-negative bacteria, which might cause less collateral damages and resistance in the resident microbiota compared to broad spectrum antibiotics [10].

\subsection{Eltrombopag Inhibits S. aureus Growth in a Cell Line Infection Model}

Previous studies suggested that the intestinal colonization of $S$. aureus may cause antibiotic-associated enterocolitis and serve as a reservoir for staphylococcal infections [11-13]. It has been reported that $S$. aureus coexists with vancomycin-resistant Enterococcus in the intestinal tract of more than $50 \%$ of American patients, raising the concern of emerging vancomycin-resistant $S$. aureus [14]. Therefore, we set up an infection model using the human intestinal Caco-2 cells to assess whether eltrombopag could eradicate colonized $S$. aureus from the intestines. Caco-2 cells were infected with $S$. aureus expressing red fluorescence protein (RFP) and treated with eltrombopag. Antibacterial activity specifically against cell invaded bacteria was determined after killing and removing extracellular bacteria by gentamicin treatment prior to eltrombopag. After a 24-h incubation, we measured eltrombopag activity by detecting $S$. aureus growth based on the RFP signal and measured Caco-2 cell viability using the CellTracker Green CMFDA Dye. We found that S. aureus growth decreased by eltrombopag in both conditions with $\left(\mathrm{MIC}_{50}=1.2 \pm 0.6 \mathrm{mg} / \mathrm{L}\right)$ and without $\left(\mathrm{MIC}_{50}=1.5 \pm 0.2 \mathrm{mg} / \mathrm{L}\right)$ gentamicin treatment similar to vancomycin (Figure $\left.3 \mathrm{~A}, \mathrm{~B}\right) . \mathrm{Cy}-$ totoxicity of eltrombopag was tested with Caco-2 and HepG2 cell lines. The 50\% inhibitory concentration $\left(\mathrm{IC}_{50}\right)$ of eltrombopag for Caco-2 and HepG2 was $202.8 \mathrm{mg} / \mathrm{L}$ and $170 \mathrm{mg} / \mathrm{L}$, respectively. The selectively index (SI) of eltrombopag was 63 for Caco-2 and 53 for HepG2 (data not shown). These results suggest that eltrombopag can be used against intestinally colonized $S$. aureus with a minimum cytotoxicity. 
A
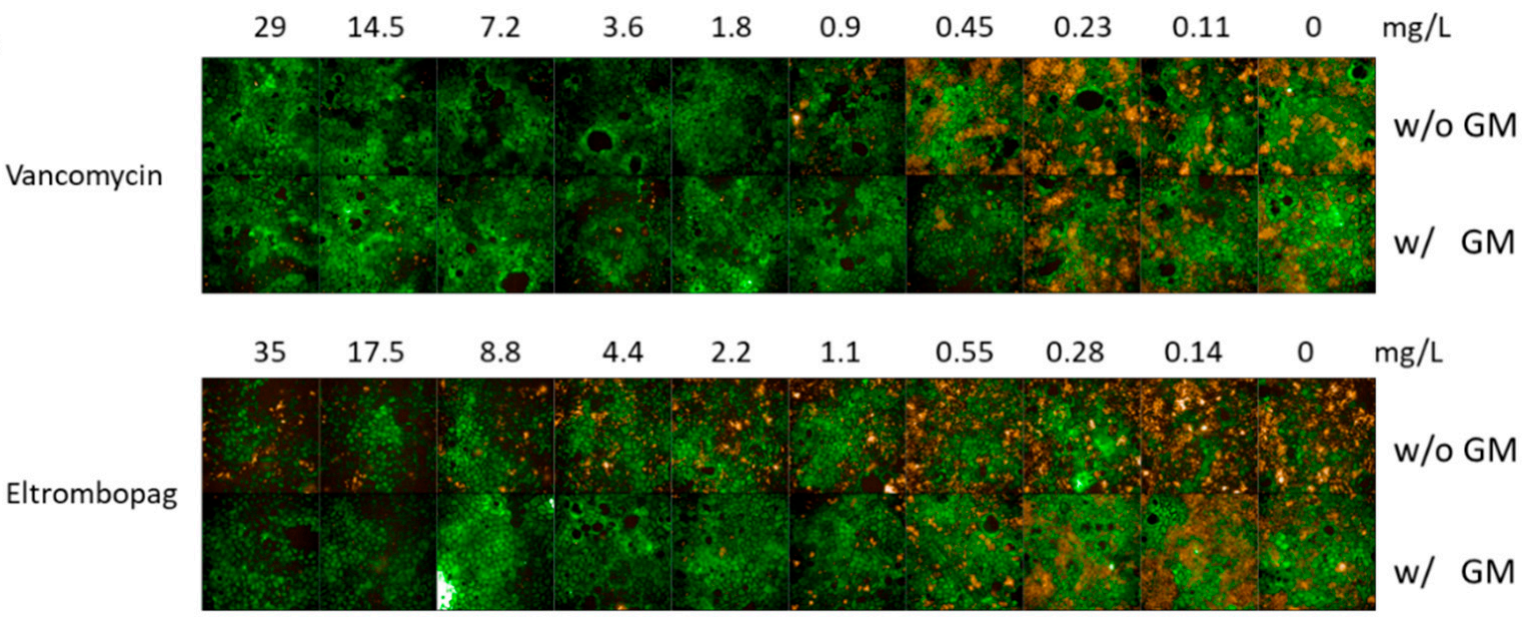

B

w/o GM

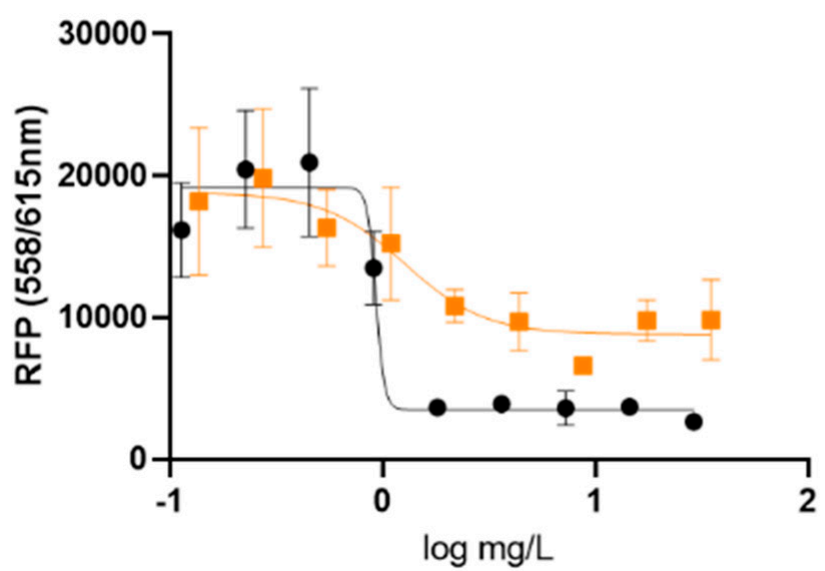

- Vancomycin

-Eltrombopag

w/ GM

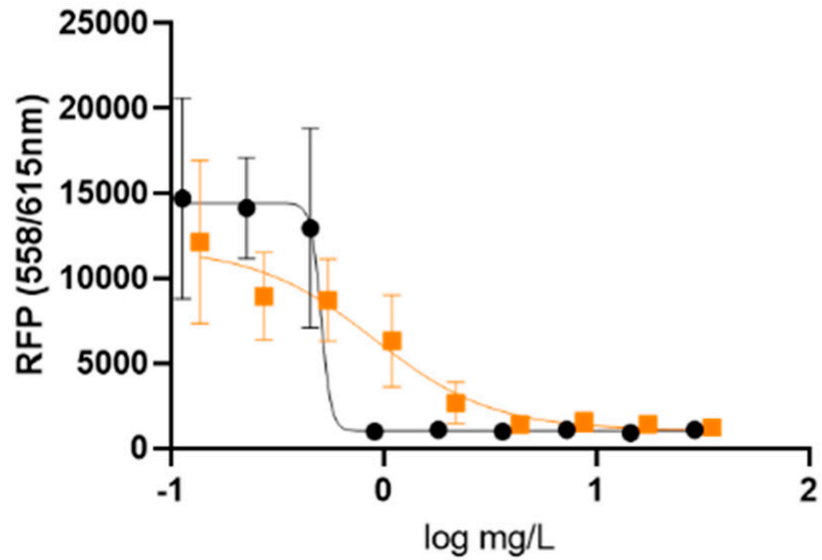

Figure 3. Ex vivo activity of eltrombopag in the Caco-2 infection model. (A) The confocal microscope images show Caco-2 cells (green) and S. aureus infection (orange) at each antibiotic concentration. (A) S. aureus infected Caco-2 cells were treated with vancomycin $(0.11-29 \mathrm{mg} / \mathrm{L})$ or eltrombopag $(0.14-35 \mathrm{mg} / \mathrm{L})$. Each experimental group was treated with or without gentamicin. (B) Dose-response curves for vancomycin $(0.11-29 \mathrm{mg} / \mathrm{L})$ and eltrombopag $(0.14-35 \mathrm{mg} / \mathrm{L})$, with or without gentamicin. The data represent the mean $\pm \mathrm{SD}(n=3$ per group). 


\subsection{In Vivo Efficacy of Eltrombopag in a Mouse Infection Model}

As eltrombopag exhibited potency in our in vitro assay and cell infection model, we then wanted to verify its in vivo efficacy in a mouse infection model. We nasally infected male C57BL/ 6 mice with $5 \times 10^{8} \mathrm{CFU}$ of $S$. aureus. At $30 \mathrm{~min}$ post-infection, we treated mice with either $50 \mathrm{mg} / \mathrm{kg}$ of vancomycin or $17.6 \mathrm{mg} / \mathrm{kg}$ of eltrombopag by intraperitoneal injection once a day for 2 days. Treatment with eltrombopag $\left(5.0 \times 10^{6} \mathrm{CFU} /\right.$ lung $)$ significantly reduced mean bacterial counts in the nasal infection model compared with control PBS $\left(5.2 \times 10^{7} \mathrm{CFU} /\right.$ lung $)$ mice $(p<0.05$; Figure 4$)$. We obtained similar results with vancomycin $\left(5.5 \times 10^{6} \mathrm{CFU} /\right.$ lung) treatment, demonstrating that eltrombopag exhibits great potential for repurposing as an antibacterial therapeutic agent, especially against S. aureus.

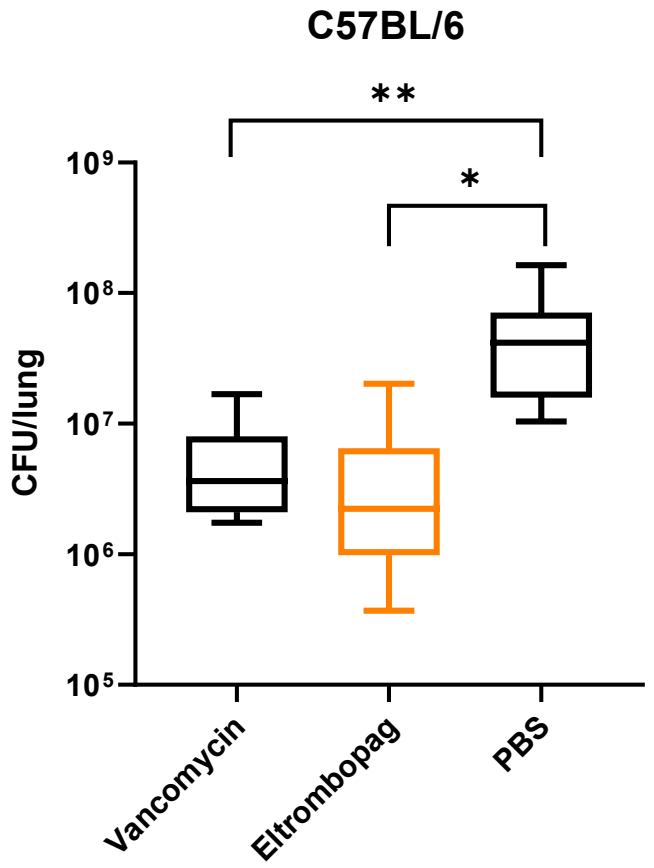

Figure 4. In vivo activity of eltrombopag in mouse nasal infection model. C57BL/C mice were infected by intranasal injection of $S$. aureus. After infection, mice were treated by intraperitoneal (IP) injection of either vancomycin or eltrombopag. Control mice received IP injection of PBS. CFU analysis showed relatively low bacterial loads in the lungs of mice treated with vancomycin $\left(5.5 \times 10^{6} \mathrm{CFU} /\right.$ lung $)$ or eltrombopag $\left(5.0 \times 10^{6} \mathrm{CFU} /\right.$ lung $)$ compared with PBS $\left(5.2 \times 10^{7} \mathrm{CFU} /\right.$ lung) controls. The data represent the mean to max values ( $n=10$ per group). Statistical significance was determined by $t$-test $\left({ }^{*}, p=0.007\right.$ and $\left.{ }^{* *}, p=0.007\right)$.

\subsection{Elucidating the Antibacterial Mechanism of Eltrombopag}

To understand the mechanism of antibacterial activity by eltrombopag, we performed a time-kill kinetics assay using tetracycline and vancomycin as bacteriostatic and bactericidal antibiotic controls, respectively. When we exposed bacteria (S. aureus ATCC25923) to each drug, vancomycin reduced the number of viable bacteria over time, whereas tetracycline did not, as expected for a bacteriostatic antibiotic (Figure 5). Similar to tetracycline, eltrombopag did not reduce the number of viable bacteria (Figure 5), suggesting that eltrombopag is a bacteriostatic agent. 


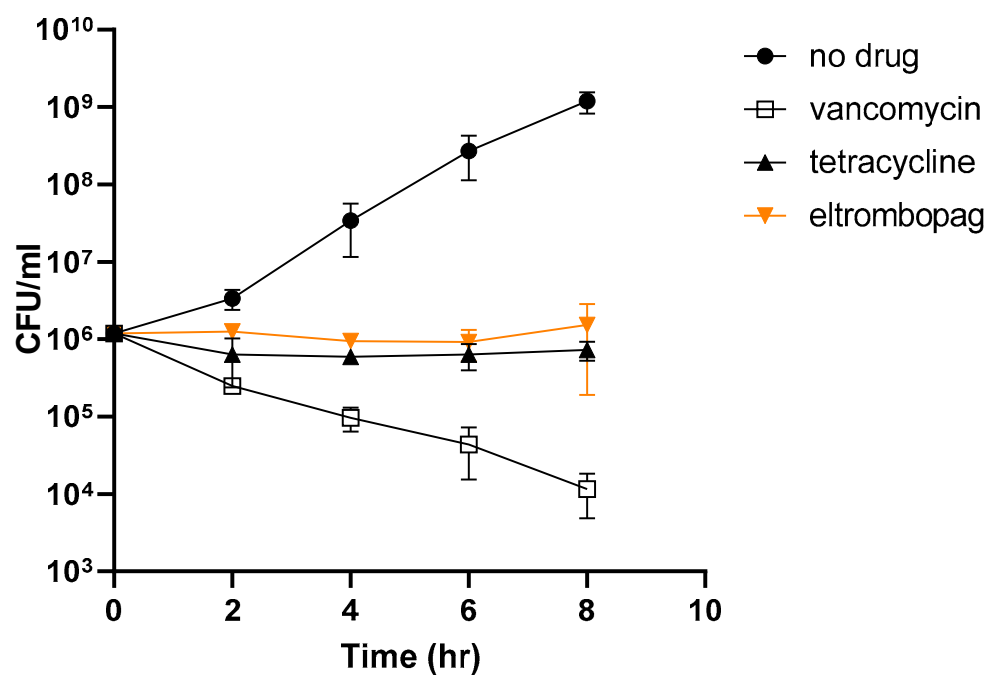

Figure 5. Bacterial killing effect of eltrombopag. Time-dependent killing of exponentially growing S. aureus wild-type (wt), with or without antibiotics (vancomycin and tetracycline) or eltrombopag. Antibiotics were tested at $2 \times$ the $\mathrm{MIC}_{50}$ value. Data represent the mean $\pm \mathrm{SD}$ ( $n=2$ per group). Each experiment was tested three times using biologically independent samples.

The efficacy of eltrombopag as a therapeutic drug for thrombocytopenia is based on its activation of TpoR by selective binding to the trans-membrane domain of the TpoR [15]. Because S. aureus does not possess any known homologs of TpoR, how eltrombopag inhibits bacterial growth remains unclear. To elucidate the antibacterial mechanism of eltrombopag, we attempted to obtain spontaneous resistant mutants by pre-exposing the bacteria at various concentrations of eltrombopag, which resulted in $5.5 \times 10^{-9}$ of a spontaneous resistant mutation frequency. Three selected resistant clones showed at least a 5-10-fold reduction of eltrombopag susceptibility (Figure 6 and Supplementary Table S2). The whole genome sequencing analysis revealed that all three sequenced resistant clones possess mutations in the same five genes: $y d e L$, (known as $p m t R$ ) a toxin-mediated transcriptional regulator, walR, a DNA-binding response regulator of WalRK two-component system, $y j b H$ (known as spxH), an adapter protein involved in Spx degradation, lytE, a $\mathrm{D}$, L-endopeptidase, and yokF, an endonuclease (Table 2). Point mutations were found in ydeL (P37L) and walR (E11G or D83G), two transcriptional regulators, which potentially alter their gene regulatory function affecting transcriptional levels of many genes in their regulons as we observed inductions of $p m t A$ and $p m t D$ in the YdeL regulon (Supplementary Figure S1). Base insertion or deletion mutations occurred in the other three genes including $y j b H$, lytE, and yokF, which likely cause complete loss of their functions resulted from protein truncation. Since the abnormal presence of autolysins and endonucleases such as LytE and YokF can cause bacterial death and these enzymes were found to be impaired in the eltrombopag resistant clones, it implies that eltrombopag-mediated bacterial growth inhibition might be associated with the activity of LytE and YokF $[16,17]$. The mutation of $y j b H$ found in the resistant mutants likely results in decreased degradation of Spx, a stress response gene regulator suggesting the pivotal role of the stress response for the bacterial resistance of eltrombopag [18]. 
S. aurues wt

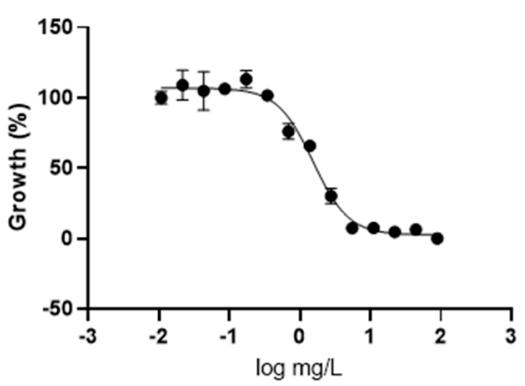

SaEr 4

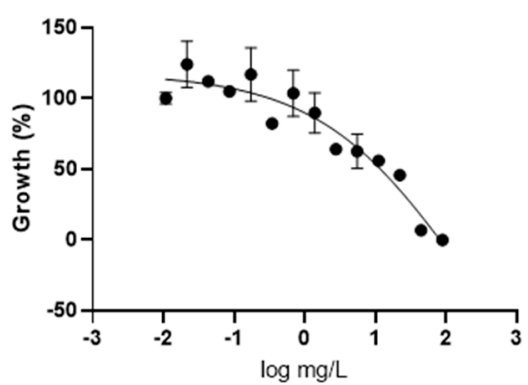

SaEr 2

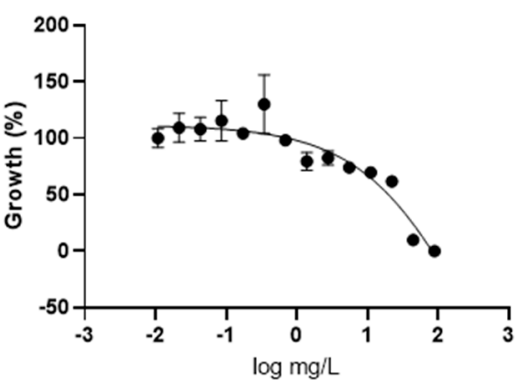

SaEr 6

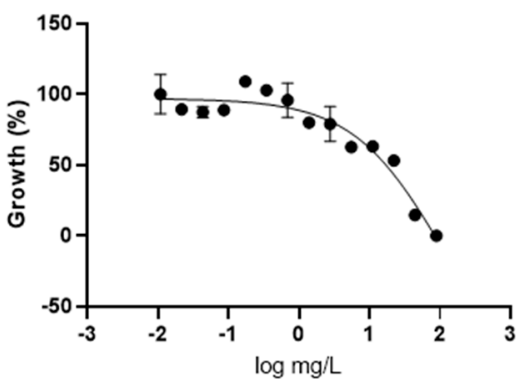

Figure 6. Antimicrobial activity of eltrombopag compound. Dose-response curve of eltrombopag (0.02-88 mg/L) against S. aureus ATCC25923 and eltrombopag resistant strains.

Table 2. Mutated gene list in eltrombopag resistant strain.

\begin{tabular}{ccc}
\hline Gene ID & Gene Name & Mutation \\
\hline SASA1_01682 & yedL $(p m t R)$ & Point mutation (P37L) \\
SASA1_01628 & walR & Point mutation (E11G or D83G) \\
SASA1_01072 & $y j b H(s p x H)$ & Truncation \\
SASA1_00966 & lytE & Truncation \\
SASA1_02364 & yokF & Truncation \\
\hline
\end{tabular}

Taken together, the genomic analysis of the resistant clones suggested that the inactivation of LytE and YokF as well as the orchestration of gene expression in the YdeL, WalR, and Spx regulons contributed to bacterial survival in the presence of eltrombopag. Further investigations remain necessary to elucidate the molecular antibacterial mechanism of eltrombopag.

\section{Materials and Methods}

\subsection{Strains and Culture Conditions}

Staphylococcus aureus ATCC25923, a pan-drug susceptible strain, Streptococcus pneumoniae ATCC49169, Streptococcus pneumoniae ATCC700904, Acinetobacter baumannii ATCC19606, Klebsiella pneumoniae ATCC13883 were purchased from the American Type Culture Collection (ATCC). Pseudomonas aeruginosa and 5 strains of multidrug resistant S. aureus were obtained from Yonsei University (Supplementary Table S1). Fifty of clinically isolates of S. aureus including 30 of methicillin-resistant S. aureus (MRSA) were obtained from Seoul National University Bundang Hospital (Supplementary Table S2). S. aureus strains were grown in Mueller-Hinton broth (MHB) (Difco) at $37^{\circ} \mathrm{C}$. Pseudomonas aeruginosa, Acinetobacter baumannii, and Klebsiella pneumoniae strains were grown in Luria-Bertani (LB) broth at $37^{\circ} \mathrm{C}$. Bacterial strain stocks were stored in vials with $25 \%$ glycerol at $-80{ }^{\circ} \mathrm{C}$. For each experiment, overnight cultures were prepared by inoculating stock in $10 \mathrm{~mL}$ of either MHB or LB broth medium and incubating at $37^{\circ} \mathrm{C}$ in a shaking incubator $(180 \mathrm{rpm})$. For the preliminary screen and dose-response experiments, $100 \mu \mathrm{L}$ of overnight culture was inoculated into $10 \mathrm{~mL}$ fresh MHB or LB broth and incubated for $3 \mathrm{~h}$ at $37^{\circ} \mathrm{C}$ and $180 \mathrm{rpm}$. 


\subsection{Primary Screening}

We performed a pilot screen of 182 FDA-approved compounds currently housed in a collection at the Institut Pasteur Korea (Seongnam-si, South Korea). We diluted frozen stock of S. aureus strain 1:100 in MHB and incubated cultures overnight at $37^{\circ} \mathrm{C}$ and $180 \mathrm{rpm}$. The overnight culture was subsequently diluted 1:100 in fresh MHB and incubated for $3 \mathrm{~h}$ at $37^{\circ} \mathrm{C}, 180 \mathrm{rpm}$ to 0.5 of $\mathrm{OD}_{600}$. We then added $40 \mu \mathrm{L}$ of $S$. aureus in each well of 348 well microplates where each compound had been dispensed at $10 \mu \mathrm{M}$ in $10 \mu \mathrm{L}$ of $0.5 \%$ dimethyl sulfoxide [DMSO]. After incubation of the plates at $37^{\circ} \mathrm{C}$ overnight, the OD was obtained using a Victor III (PerkinElmer, Waltham, MA, USA).

\subsection{Dose-Response of Selected Repositionable Candidates}

We conducted antibiotic susceptibility testing according to modified Clinical and Laboratory Standards Institute (CLSI) laboratory guidelines for broth microdilution assays [19]. We inoculated bacterial cultures (S. aureus, P. aeruginosa, A. baumannii, and K. pneumoniae) in MHB or LB until cultures and prepared bacterial cells $\mathrm{OD}_{600}$ of 0.05 . DRC plates were prepared by adding $45 \mu \mathrm{L}$ bacterial suspension to each well where $5 \mu \mathrm{L}$ of each compound had been dispensed for 13 points of two-fold serial dilutions starting at $22 \mathrm{mg} / \mathrm{L}$. After incubation of the plates at $37^{\circ} \mathrm{C}$ for $18-24 \mathrm{~h}$ with $5 \% \mathrm{CO}_{2}$, we detected S. aureus growth by measuring the $\mathrm{OD}_{600}$ using a Victor III spectrometer.

\subsection{Effect of Eltrombopag on S. aureus Infection of Human Caco-2 Cells}

We used the human intestinal cell line Caco-2 in ex vivo antimicrobial activity tests of eltrombopag and vancomycin as a positive control drug. We cultured Caco-2 cells in minimum essential media (MEM) with $10 \%$ fetal bovine serum (FBS) and $1 \times$ non-essential amino acids in a 96-well microplate at $37^{\circ} \mathrm{C}$ and $5 \% \mathrm{CO}_{2}$. After Caco-2 cells reached full confluence, we grew the cells and changed media every 2 days for 5 more days to obtain differentiated cells in 384-well plates, as described in previous reports, with some modifications (Materials and Methods) [20-22]. We cultured S. aureus (ATCC25923 containing a pHC48 encoding dsRedExpress) in MHB with $10 \mu \mathrm{g} / \mathrm{mL}$ of chloramphenicol and harvested bacteria cells [23]. After washing the bacterial cells with phosphate-buffered saline (PBS) and suspending them in MEM, we infected Caco-2 cells with S. aureus $\left(1 \times 10^{7} \mathrm{CFU}\right)$ and incubated them for $2.5 \mathrm{~h}$. We then treated cells with gentamicin $(50 \mu \mathrm{g} / \mathrm{mL}$ of gentamicin in MEM) and incubated plates for $1 \mathrm{~h}$. We washed samples two times with PBS, added MEM containing diluted compounds, and incubated plates at $37^{\circ} \mathrm{C}$ in $5 \% \mathrm{CO}_{2}$ for $24 \mathrm{~h}$. We added CellTrackerTM Green 5-Chloromethylfluorescein diacetate (CMFDA) Dye (Thermo Fisher Scientific, Waltham, MA, USA) to stain live Caco-2 cell, incubated the plates for $1 \mathrm{~h}$, and imaged the plates using Operetta CLS (PerkinElmer, Waltham, MA, USA) to obtain images. To detect the dsRedExpress fluorescent protein (RFP) signal, we used an Ensight multimode plate reader (PerkinElmer, Waltham, MA, USA).

\subsection{Cytotoxicity Test of Eltrombopag}

We used the human liver cell line HepG2 and intestinal cell line Caco-2 in the cytotoxicity test of eltrombopag. We cultured HepG2 and Caco-2 cells in DMEM with 10\% fetal bovine serum (FBS) in a 96-well microplate at $37^{\circ} \mathrm{C}$ and $5 \% \mathrm{CO}_{2}$. HepG2 and Caco-2 cells were seeded at a final density of $5 \times 10^{4}$ cells/well and DMEM containing diluted compounds was added, and the plates were incubated at $37^{\circ} \mathrm{C}$ in $5 \% \mathrm{CO}_{2}$ for $24 \mathrm{~h}$. We added resazurin (final concentration, $0.1 \mathrm{mg} / \mathrm{mL}$ ) to each well and, incubated the plates at $37{ }^{\circ} \mathrm{C}$ in $5 \% \mathrm{CO}_{2}$ for $2 \mathrm{~h}$. To detect the fluorescence at $530 \mathrm{~nm}$ excitation and $590 \mathrm{~nm}$ emission, we used an Ensight multimode plate reader (PerkinElmer, Waltham, MA, USA). Selective activities of the compounds were calculated as follows:

Selectivity index $(\mathrm{SI})=\mathrm{IC}_{50}$ cell lines $/ \mathrm{IC}_{50}$ inhibition concentration to bacterial growth 


\subsection{Mouse Infection Model}

7-week-old C57BL/ 6 male mice (Orient Bio, Inc., Seongnam-si, South Korea) weighing 20-22 g were used to test the in vivo antimicrobial activity of eltrombopag against $S$. aureus ATCC25923 (protocol approved by The Animal Care and Ethics Committee of IPK, Approval numbers IPK-19006 and IPK-20009). We injected S. aureus $\left(5 \times 10^{8} \mathrm{CFU}\right.$ suspended in $40 \mu \mathrm{L}$ PBS) into the nasal cavities of anesthetized mice ( $n=10$ per group). At $30 \mathrm{~min}$ post-infection, eltrombopag (17.6 mg/ $\mathrm{kg}$ body weight) and vancomycin $(50 \mathrm{mg} / \mathrm{kg}$ body weight) were administrated by intraperitoneal injection two times $24 \mathrm{~h}$ apart. Due to the lower solubility of eltrombopag, $17.6 \mathrm{mg} / \mathrm{kg}$ was the highest solubilized concentration we tested in this study. A control group was injected with PBS in the same volume and frequency as mice receiving treatment. After $24 \mathrm{~h}$, we sacrificed the mice and collected lung tissue. We homogenized the collected lung tissue in $1 \mathrm{~mL}$ PBS, serially diluted the homogenate, and plated dilutions on LB plates. We incubated plates for $18-24 \mathrm{~h}$ at $37^{\circ} \mathrm{C}$ and counted bacterial colonies to determine the CFU.

\subsection{Kinetics of Time-Dependent Bacterial Killing}

We diluted overnight cultures of S. aureus ATCC25923 to $10^{6} \mathrm{CFU} / \mathrm{mL}$ in $10 \mathrm{~mL}$ MHB supplemented with an MIC of antimicrobials (vancomycin, tetracycline, and eltrombopag) and incubated cultures at $37^{\circ} \mathrm{C}$ with shaking at $180 \mathrm{rpm}$. We collected bacterial cells $(0.1$ $\mathrm{mL}$ ) from the culture at different incubation times, serially diluted collected cells with PBS, and plated cells on $\mathrm{MH}$ agar plates. We counted surviving colonies after incubating plates for $24 \mathrm{~h}$ at $37^{\circ} \mathrm{C}$. We repeated each experiment three times in duplicate.

\subsection{Eltrombopag-Resistant Mutant Selection}

To generate an eltrombopag-resistant mutant of $S$. aureus, we cultured bacterial cells in MHB at $37^{\circ} \mathrm{C}$. We harvested cells at the early stationary phase of $S$. aureus growth and suspended the cells in MHB at $2 \times 10^{9} \mathrm{CFU} / 100 \mu \mathrm{L}$. We plated S. aureus on $\mathrm{MH}$ agar plates with various concentrations of eltrombopag $(2.2,4.4$, and $8.8 \mathrm{mg} / \mathrm{L})$ and grew them at $37^{\circ} \mathrm{C}$ overnight. After incubation, we obtained 11 colonies that showed 2 to 4 fold increased $\mathrm{MIC}_{50}$ values compared to the parental strain (Spontaneous resistant mutation frequency: $\left.5.5 \times 10^{-9}\right)$. Among 11 resistant colonies, 4 of them were selected either the whole genome sequencing or RT-qPCR analyses for subsequent investigations.

\subsection{Whole-Genome Sequencing Analysis}

We cultured eltrombopag-resistant S. aureus in MHB at $37^{\circ} \mathrm{C}$ overnight and harvested cells for isolation of genomic DNA using the Wizard Genomic DNA Purification Kit (Promega, Madison, WI, USA. Genomic DNA sequences were analyzed by Illumina Miseq (CLgenomics, Chunlab, Seoul, Korea).

\subsection{RNA Extraction and $q R T-P C R$}

Total RNA of $S$. aureus and eltrombopag resistance strains were extracted using RNeasy Mini Kit (Qiagen, Hilden, Germany) following the manufacture's protocol. RNA concentration was quantified by NonoVue Spectrophotometer (GE Healthcare, Chicago, USA). RT-qPCR was accomplished using the QuantiFast SYBR Green RT-PCR Kit (Qiagen, Hilden, Germany) on an ViiA7 Real-Time CRP System (Thermofisher Scientific, Waltham, MA, USA), following the program: $10 \mathrm{~min}$ at $50{ }^{\circ} \mathrm{C}, 5 \mathrm{~min}$ at $95^{\circ} \mathrm{C}$, followed by 40 cycles of $10 \mathrm{sec}$ at $95^{\circ} \mathrm{C}, 10 \mathrm{sec}$ at $55^{\circ} \mathrm{C}$, and $20 \mathrm{sec}$ at $72^{\circ} \mathrm{C}$. The relative quantification of mRNA was performed by the comparative CT $\left(2^{-\Delta \Delta \mathrm{CT}}\right)$ method, with the tRNA gene as an internal control. The primers designed for $t R N A$ (F 5'-GATGATTGAAGGGGAAATGG-3', $\mathrm{R} 5^{\prime}$ GGTGTCGCAACTTTTTCAAG- $3^{\prime}$ ), pmtA (F $5^{\prime}$-ACTTAAGTGACGGTGAAGTTATC- $3^{\prime}$, R $5^{\prime}$ - TGCGCATGTTCTGTTAATCCT-3'), and $p m t D$ (F $5^{\prime}$-TGGCAAATTCGATGGATAACCC$3^{\prime}$, R $5^{\prime}$ - TCACGCGTAATTGTCTTAACAAC-3') are constructed and used in this study. 


\subsection{Statistical Analysis}

We performed all statistical analysis (t-test) using GraphPad Prism 8.0 software (GraphPad Software, San Diego, CA, USA).

\section{Conclusions}

Here, we screened 182 FDA-approved drugs to identify new therapeutic entities for stapnylococcus infections. Among 12 drugs identified with potential antibacterial activity, eltrombopag, a drug approved for thrombocytopenia, showed the most significant antibacterial activity against multidrug-resistant $S$. aureus. We confirmed that eltrombopag effectively inhibits the growth of $S$. aureus demonstrating its activity in in vitro assays of 55 clinical isolates and the cell infection model as well as in vivo assays, proposing a possible mechanism of eltrombopag-mediated bacterial growth inhibition. These results suggest the potential of eltrombopag as a repurposed drug for the treatment of multidrug resistant S. aureus infections, which have very limited therapeutic options. More investigations should be followed to assess potential adverse effects of eltrombopag as an antibacterial agent and to elucidate its antibacterial mechanism for further clinical development.

Supplementary Materials: The following are available online at https:/ /www.mdpi.com/article/ 10.3390/antibiotics10111372/s1, Figure S1: pmt $A$ and $p m t D$ expression level (2- $\Delta \Delta \mathrm{Ct})$ in the S. aureus ATCC25923 and eltrombopag resistant strains (SaEr 12, 2, 4, and 6), Table S1: Summary of antimicrobial activities of methicillin resistant Staphylococcus aureus (MRSA), Table S2: Summary of antimicrobial activities of Gram-positive and Gram-negative.

Author Contributions: H.L. (Hyunjung Lee) and S.J. conceptualized the study and designed the experiments, analyzed the results, and wrote the manuscript. J.L., J.H., S.P., and N.K. performed the experiments and analyzed the results. K.K., H.L. (Honggun Lee), and D.S. supported and managed of compounds resources. All authors have read and agreed to the published version of the manuscript.

Funding: Please add: This research was funded by a National Research Foundation of Korea (NRF) grant funded by the Korean government (MSIT) (NRF-2017M3A9G6068246 \& 2019M3E5D5064653).

Institutional Review Board Statement: This study was carried out in strict accordance with the recommendations in the guide for the care and use of animal facilities. The protocol was approved by the Animal Care and Ethics Committee of Institut Pasteur Korea (approval IPK-19006 and IPK-20009).

Informed Consent Statement: Not applicable.

Data Availability Statement: Not applicable.

Acknowledgments: We thank Hong Bin Kim in Seoul National University Bundang Hospital and Dongeun Yong in Yonsei University for kindly providing clinical isolates.

Conflicts of Interest: The authors declare no conflict of interest.

\section{References}

1. McGuinness, W.A.; Malachowa, N.; DeLeo, F.R. Vancomycin Resistance in Staphylococcus aureus. Yale J. Biol. Med. 2017, 90, 269-281.

2. Beyer, P.; Paulin, S. Priority pathogens and the antibiotic pipeline: An update. Bullet. World Health Organ. 2020, 98, 151. [CrossRef]

3. Thakare, R.; Singh, A.K.; Das, S.; Vasudevan, N.; Jachak, G.R.; Reddy, D.S.; Dasgupta, A.; Chopra, S. Repurposing Ivacaftor for treatment of Staphylococcus aureus infections. Int. J. Antimicrob. Agents 2017, 50, 389-392. [CrossRef]

4. Jeon, S.; Ko, M.; Lee, J.; Choi, I.; Byun, S.Y.; Park, S.; Shum, D.; Kim, S. Identification of Antiviral Drug Candidates against SARS-CoV-2 from FDA-Approved Drugs. Antimicrob. Agents Chemother. 2020, 64, e00819-20. [CrossRef]

5. Ittzes, B.; Szentkiralyi, E.; Szabo, Z.; Batai, I.Z.; Gyorffy, O.; Kovacs, T.; Batai, I.; Kerenyi, M. Amiodarone that has antibacterial effect against human pathogens may represent a novel catheter lock. Acta Microbiol. Immunol. Hung. 2020, 67, $133-137$.

6. Chang, H.C.; Huang, Y.T.; Chen, C.S.; Chen, Y.W.; Huang, Y.T.; Su, J.C.; Teng, L.J.; Shiau, C.W.; Chiu, H.C. In vitro and in vivo activity of a novel sorafenib derivative SC5005 against MRSA. J. Antimicrob. Chemother. 2016, 71, 449-459. [CrossRef]

7. Le, P.; Kunold, E.; Macsics, R.; Rox, K.; Jennings, M.C.; Ugur, I.; Reinecke, M.; Chaves-Moreno, D.; Hackl, M.W.; Fetzer, C.; et al. Repurposing human kinase inhibitors to create an antibiotic active against drug-resistant Staphylococcus aureus, persisters and biofilms. Nat. Chem. 2020, 12, 145-158. [CrossRef] 
8. Li, S.; Qi, X.; Huang, Y.; Liu, D.; Zhou, F.; Zhou, C. Ceritinib (LDK378): A potent alternative to crizotinib for ALK-rearranged non-small-cell lung cancer. Clin. Lung Cancer 2015, 16, 86-91. [CrossRef]

9. Gonzalez-Porras, J.R.; Bastida, J.M. Eltrombopag in immune thrombocytopenia: Efficacy review and update on drug safety. Ther. Adv. Drug Saf. 2018, 9, 263-285. [CrossRef]

10. Melander, R.J.; Zurawski, D.V.; Melander, C. Narrow-Spectrum Antibacterial Agents. Medchemcomm 2018, 9, 12-21. [CrossRef]

11. Lane, A.B.; Copeland, N.K.; Onmus-Leone, F.; Lawler, J.V. Methicillin-Resistant Staphylococcus aureus as a Probable Cause of Antibiotic-Associated Enterocolitis. Case Rep. Infect. Dis. 2018, 2018, 3106305. [CrossRef]

12. Acton, D.S.; Plat-Sinnige, M.J.T.; van Wamel, W.; de Groot, N.; van Belkum, A. Intestinal carriage of Staphylococcus aureus: How does its frequency compare with that of nasal carriage and what is its clinical impact? Eur. J. Clin. Microbiol. 2009, 28, 115-127. [CrossRef]

13. Squier, C.; Rihs, J.D.; Risa, K.J.; Sagnimeni, A.; Wagener, M.M.; Stout, J.; Muder, R.R.; Singh, N. Staphylococcus aureus rectal carriage and its association with infections in patients in a surgical intensive care unit and a liver transplant unit. Infect. Cont. Hosp. Epidemiol. 2002, 23, 495-501. [CrossRef] [PubMed]

14. Ray, A.J.; Pultz, N.J.; Bhalla, A.; Aron, D.C.; Donskey, C.J. Coexistence of vancomycin-resistant enterococci and Staphylococcus aureus in the intestinal tracts of hospitalized patients. Clin. Infect. Dis. 2003, 37, 875-881. [CrossRef] [PubMed]

15. Erickson-Miller, C.L.; DeLorme, E.; Tian, S.S.; Hopson, C.B.; Stark, K.; Giampa, L.; Valoret, E.I.; Duffy, K.J.; Luengo, J.L.; Rosen, J.; et al. Discovery and characterization of a selective, nonpeptidyl thrombopoietin receptor agonist. Exp. Hematol. 2005, 33, 85-93. [CrossRef] [PubMed]

16. Linzner, N.; Van Loi, V.; Fritsch, V.N.; Antelmann, H. Thiol-based redox switches in the major pathogen Staphylococcus aureus. Biol. Chem. 2021, 402, 333-361. [CrossRef] [PubMed]

17. Vollmer, W.; Joris, B.; Charlier, P.; Foster, S. Bacterial peptidoglycan (murein) hydrolases. FEMS Microbiol. Rev. 2008, 32, 259-286. [CrossRef] [PubMed]

18. Sakamoto, J.J.; Sasaki, M.; Tsuchido, T. Purification and characterization of a Bacillus subtilis 168 nuclease, YokF, involved in chromosomal DNA degradation and cell death caused by thermal shock treatments. J. Biol. Chem. 2001, 276, 47046-47051. [CrossRef] [PubMed]

19. Methods for Dilution Antimicrobial Susceptibility Tests for Bacteria That Grow Aerobically, Approved Standard, 9th ed.; Clinical and Laboratory Standards Institute: Wayne, PA, USA, 2012.

20. Ferruzza, S.; Rossi, C.; Scarino, M.L.; Sambuy, Y. A protocol for differentiation of human intestinal Caco-2 cells in asymmetric serum-containing medium. Toxicol. In Vitro 2012, 26, 1252-1255. [CrossRef]

21. Mariadason, J.M.; Arango, D.; Corner, G.A.; Aranes, M.J.; Hotchkiss, K.A.; Yang, W.C.; Augenlicht, L.H. A gene expression profile that defines colon cell maturation in vitro. Cancer Res. 2002, 62, 4791-4804. [PubMed]

22. Sambuy, Y.; Angelis, I.; Ranaldi, G.; Scarino, M.L.; Stammati, A.; Zucco, F. The Caco-2 cell line as a model of the intestinal barrier: Influence of cell and culture-related factors on Caco-2 cell functional characteristics. Cell Biol. Toxicol. 2005, 21, 1-26. [CrossRef] [PubMed]

23. Ibberson, C.B.; Parlet, C.P.; Kwiecinski, J.; Crosby, H.A.; Meyerholz, D.K.; Horswill, A.R. Hyaluronan Modulation Impacts Staphylococcus aureus Biofilm Infection. Infect. Immun. 2016, 84, 1917-1929. [CrossRef] [PubMed] 